\title{
IoT Based Solar Powered Smart Waste Management System with Real Time Monitoring-An Advancement for Smart City Planning
}

\author{
By Md. Humaun Kabir, Sujit Roy, Md. Tofail Ahmed \& Mahmudul Alam \\ Bangamata Sheikh Fojilatunnesa Mujib Science and Technology University
}

Abstract- In this paper, we proposed an loT based solar-powered smart waste management system which is suitable for any kind city or town in both developed and developing countries that can ensure proper collection, transportation, and disposal of household and industrial waste with real-time remote monitoring. To maintain the green and clean environment around us, precise collection and disposal of garbage in a regular fashion are necessary. The primary goal of this research work is to provide a complete smart solution for waste collection and disposal hence ensuring a comfortable environment. The proposed system enables real-time remote monitoring of solar-powered several smart bins located in different points in the city which are connected to the control station through long-range (LoRa) communication device and also supervises the waste collector activities like collection and disposal time using Automated Vehicles Locating System (AVLS).

Keywords: IOT, smart bin, smart city planning, WSN, E32- TTL-100 LoRa module, AVLS, arduino mega, US sensor, PIR sensor, GSM module, solar power.

GJCST-G Classification: C.5.m

Strictly as per the compliance and regulations of:



(C) 2020. Md. Humaun Kabir, Sujit Roy, Md. Tofail Ahmed \& Mahmudul Alam. This is a research/review paper, distributed under the terms of the Creative Commons Attribution-Noncommercial 3.0 Unported License http://creativecommons.org/licenses/by$\mathrm{nc} / 3.0 /$ ), permitting all non-commercial use, distribution, and reproduction in any medium, provided the original work is properly cited. 


\title{
IoT Based Solar Powered Smart Waste Management System with Real Time Monitoring- An Advancement for Smart City Planning
}

\author{
Md. Humaun Kabir ${ }^{\alpha}$, Sujit Roy ${ }^{\sigma}$, Md. Tofail Ahmed ${ }^{\rho} \&$ Mahmudul Alam $^{\omega}$
}

\begin{abstract}
In this paper, we proposed an loT based solarpowered smart waste management system which is suitable for any kind city or town in both developed and developing countries that can ensure proper collection, transportation, and disposal of household and industrial waste with real-time remote monitoring. To maintain the green and clean environment around us, precise collection and disposal of garbage in a regular fashion are necessary. The primary goal of this research work is to provide a complete smart solution for waste collection and disposal hence ensuring a comfortable environment. The proposed system enables realtime remote monitoring of solar-powered several smart bins located in different points in the city which are connected to the control station through long-range (LoRa) communication device and also supervises the waste collector activities like collection and disposal time using Automated Vehicles Locating System (AVLS). Another back-up/ extra conventional bin along with the smart bin in each point is reserved for emergency use. The system framework integrates multiple technologies such as solar system, wireless sensor networks (WSN), loT, cloud computing, and shortest route-finding method etc. Within this framework there will be six developed subsystems: renewable energy source, multiple smart waste bin, SMS notification system, automated vehicles tracking system, web-based real-time monitoring system and shortest route generation system that all subsystems are interrelated to each other to work as a highly efficient waste management system with reduced cost and time that yield to the healthy and living environment around us.
\end{abstract}

Keywords: IOT, smart bin, smart city planning, WSN, E32TTL-100 LoRa module, AVLS, arduino mega, US sensor, PIR sensor, GSM module, solar power.

\section{INTRODUCTION}

W aste management is one of the core concerns of the modern age in each developed and developing countries. As nations around the world are improving, their responsibilities and accountability for a healthier and sustainable environment are also increasing. There are numerous

Author a $\sigma$ w: Faculty Member, Department of Computer Science and Engineering, Bangamata Sheikh Fojilatunnesa Mujib Science and Technology University, Jamalpur-2000, Bangladesh. e-mail: humaun4938@gmail.com

Author $\rho$ : Faculty Member, Department of Information and Communication Engineering, Bangladesh Army University of Engineering and Technology, Natore-6431, Bangladesh. categories and each with different classifications of waste materials, like clinical to nuclear, biodegradable to non-bio-degradable, and general household to industrial toxic waste [1-3]. While developed countries are inventing and implementing smart solutions for waste management and bringing about enormous positive impacts in real life, several developed countries can manage and treat these waste materials of different categories. However, developing countries are still struggling with the collections and proper disposal of usual household and industrial waste materials. Disorganized management and dumping of garbage at any place are one of the serious causes for ruining the environment in the major cities of these developing countries [4-6]. In developing countries like Bangladesh, rapid urbanization and industrialization transition happened at different municipal cities like Dhaka. Due to rapid development in the urban areas in the developing countries, the characteristics of the solid wastes have changed, and the generation of municipal solid waste (MSW) over the last ten years has increased immensely. There are many public places in the cities and towns where garbage bins or dustbins are placed but are overflowing which causes unhygienic conditions and ugliness in the nearby surrounding. It also creates air pollution and at the same time a strong unpleasant smell is also spread around the region. As a result, people may be affected by some serious diseases, and it also degrades the valuation of that area. Implementing existing solutions for waste management systems in developing countries is a prime challenge due to many different factors like socio-economic environment, and unplanned infrastructural issues [7-9]. Waste is carried and thrown improperly, leading to an unhealthy and inhabitable environment that costs the government an insane amount of money with not at all positive impact. Therefore, trash need to be packed, dumped, collected, transported, manipulated, and recycled properly in such ways that waste materials become a precious wealth of a country. To achieve this goal, we proposed a novel framework for waste management. The mentioned IoT based solar-powered waste management system can be an efficient, cost-effective and smart solution for proper waste collection, real-time remote monitoring, and disposal that could ensure a clean, healthy, and green environment in our surroundings. 


\section{RELATED WORKS}

Many researchers of academic institutions and industries have been working on different applications for smart cities equipped with loT facilities. They proposed several solutions for proper waste management in the urban areas considering the advantages of IoT technologies in the literature; few related works are described briefly in this paper. In [10], authors used platform software for smart cities to improve waste management, but they only concentrated on the collection of data. However, some approaches have developed waste management strategies based on the optimization to realize an efficient system in this paper. The authors introduced an IoT based waste control and management system using LoRa WAN technology and route optimization technique suitable for rural areas in [11]. But the system did not provide clarity about communication and optimization for all garbage bins. In [12], the authors worked on optimal path planning for an automated waste collection system. However, this paper is based on loT cloud solution combining device connection, data processing, and control, rather than the design and optimization of waste collection. Authors presented a simple system to save power consumption in [13] that identifies the fullness of trash bins, which collected data and delivered it through a wireless mesh network and maximize operational time. But the idea still has some ambiguous problems in the system. In [14], some optimization algorithms- the nearest neighbor search, colony optimization, genetic algorithm, and particle swarm optimization methods have been proposed for loT-based waste management. The authors proposed a garbage management system that has an autonomous line-following vehicle with a robotic hand for garbage collection, but they did not apply any algorithms to optimize the waste collection [15-16]. In [17], the authors provide a smart waste bin suitable for apartment and flat type residential house that has trash chute. This system uses a US sensor to measure the waste level and Arduino Mega as a microcontroller, which sends a notification through SMS to collector whenever the waste bin is almost full. The authors have designed an loT based waste management system using an 8051 microcontroller in [18], which can detect waste level in the dustbin and avoid the overflow of it. The transmitter section including the microcontroller, RF transmitter, and sensors is attached to the trash bin. On the other hand, RF receiver, Intel Galileo, and Web Browser are used in the receiver section. Another work in [19], the dustbin interfaced with a microcontroller based system having IR sensors and connected with the central system through Wi-Fi that shows the current status of garbage on the web page of mobile. In [20], the network of sensors enabled smart bins connected through the cellular network generates a large amount of data, which is further analyzed and visualized to obtain the real-time data of waste around the city. Authors have developed Smart Waste Management System (SWMS) that manipulates geospatial technology and intelligence sensors like US sensor via IOT technology for reliable Smart City and M2M solutions in [21]. The proposed system may reduce the workload of the waste collectors by recording the collection process. Scattered waste around the dustbin is monitored using IR sensors, and the low-cost camera is used to maintain the cleanliness and hygiene of the city in [22]. In this paper, we have tried to find ways to minimize the total cost of waste collection and transport, save labor, and reduce the dependency on usual vehicles while maximizing the quality of service as well as improving the general quality of life.

\section{ili. Problem Statement}

There are several limitations in a large number of developed and developing countries found in the existing technologies and techniques used for waste management. The proposed system framework considers the following problems and restrictions as guidelines:

1. Smart bin has not been used in most developing countries like Bangladesh yet commercially though the technological supports are available.

2. No central real-time monitoring on different waste bins and waste collector/ trucks.

3. No way for garbage level detection and updating the status of the bins to respective authorities.

4. No way to open and close the lid of the trash container automatically to make it a touch-free dustbin.

5. There is no way to close the top of the dustbin permanently when it will be full until it's empty again.

6. Lack of information about the collection time, disposal time, and collection area. There is no way to notify the waste collectors in real-time to collect the waste urgently.

7. There is no estimation of the amount of solid waste inside the bin and the surrounding area due to the scattering of waste.

8. No quick way to respond to client's complaints about uncollected garbage.

9. No reserved ordinary bin with the smart bin in each point is available for emergency use.

10. There is no quick response to urgent cases like a truck accident, breakdown, longtime idling, etc.

11. There is no analysis of finding the best/ shortest route of collecting waste from different bins located in several points in the city to instruct the collectors.

\section{The Proposed System}

The WSNs based proposed system framework shown in figure 1 incorporates several related 
subsystems: solar power system, smart waste bins, SMS notification system, web-based real-time monitoring system, AVLS, and web-based shortest route-finding system for the collectors. The number of the smart bin (SB1, SB2,..., SBn, where $\mathrm{n}$ is an integer) along with conventional bin situated in a different location in a city area and the number of the waste collector (WC1, WC2, ..., WCn, where $\mathrm{n}$ is an integer) under a control station depends on the size of that city and amount of waste generated per day in that area. Figure 1 presents the pictorial scenario of several SBs with back-up CBs located in different points in a city. An additional back-up normal bin is located with the smart bin at each point of an urban area for emergency use. If the lid of the smart bin is locked permanently due to technical problems or any kind of issues arises like a truck/ collector accident, breakdown, longtime idling etc., then the back-up ordinary bin can be used instead of smart bin to ensure garbage-free surroundings. Smart bins collect data from different sensors integrated with it and then transmit bin status and related information to the control room using WSNs via wireless communication. The control station receives the data from the multiple smart bins and stores in the database and also visualizes the acknowledged data. SMS notification system integrated with each SB automatically identifies the fully loaded condition of waste bin and it sends an alert notification to the control station in real-time, then updates the waste bin status shown in LCD and also turn on the Red LED mounted at the smart bin. Till the dustbin is empty again, the lid will remain locked. After getting the alert notification from multiple SBs, control station will generate a shortest route in the map and sends it to the collector with collection time so that collector can do the collection and disposal activities within a very short time. After the waste bin has been emptied, the smart waste bin will update the bin status and transmit the information again to the control station. A web-based application is developed to monitor and coordinate all smart bins status, collection, and disposal activities in real-time.

\section{Reguirement Analysis}

The following hardware and software components are used in our works.

a) Hardware Requirements

i. Solar panel, solar controller, battery pack \& regulation circuit

ii. Arduino Mega

iii. Servo motor with motor driver \& metallic gear

iv. PIR Sensor

v. US sensor

vi. LCD

vii. GSM module with SIM

viii. E32-TTL-100 LoRa module

ix. Automated Vehicles Locating System (AVLS) x. Robot car kit etc.

\section{b) Software Requirements}

i. Bootstrap, JavaScript and PHP language-based web application

ii. MySQL based database

iii. Google maps API premier service etc.

\section{Design And Implementation}

The proposed system consists of different segments, and each segment facilitates several subsystems that will execute separate tasks. Every hardware and software incorporated with this system is described briefly in this section.

\section{a) Solar Energy System}

Solar energy, the cleanest and most available renewable energy source in the world, is used to provide regulated power to the different parts of smart bins. The solar power system is built by assembling the solar panels, solar charger controller and, rechargeable battery as shown in figure 2. Solar panel absorbs the solar energy from the incident light rays from the sun and converts it into electric energy. The solar charger controller is used to regulate the amount of charge flowing from the panel into the battery pack and protect the battery bank being overcharged. The regulation circuit provides regulated power to the different modules and sensor systems of the smart bins.

\section{b) Touch-Free Smart Bin}

The implemented smart waste bin depicted in figure 3 incorporates wireless sensor network (WSN) technology interfaces with an Arduino Mega microcontroller. Smart Bin is an idea of implementation which makes a conventional dustbin smart using sensors for garbage level detection and sending a notification to concerned authorities updating the status of the bin using wireless communication technology. The implemented smart bins in this work are touch-free dustbin, passive infrared sensor (PIR) motion sensors are used to detect garbage level and ultrasonic sensor (US) sensor is used to identify the presence of a person. When any person reaches near to it, the lid of the bin will open automatically, so there is no need to open that dirty lid by your hands. Servo motor is used to open and close the lid of dustbin in a self-acting way. An LCD is integrated with bin to show the real-time status of it. Fill level inside the waste container is presented in the LCD using three states like $0 \%$ full, $50 \%$ full, and $90 \%$ full. As soon as the garbage inside the dustbin reaches as the approximate level of $90 \%$ that tells the user not to use this dustbin, and Red LED will be turned on until it's empty again. Till the trash-bin is vacant, the lid will not open so that no one can through garbage into it and create a mess. In addition, this smart bin also includes a Green LED to indicate that the dustbin is Empty 
condition ( $0 \%$ full) and a Yellow LED to indicate the Half loaded situation (50\% full).

Three different color LEDs will help people to know from a distance that whether we should go to dump our garbage in the particular dustbin or not, also helpful to uneducated persons who don't read the notification shown in the LCD. Different conditions for fill level indication are summarized in table 1. All the realtime data from smart waste bin which comprise of the waste bin id, fill-level measurement, timestamp, and status then transmitted to the control station through E32-TTL-100 long range (LoRa) wireless communication module.

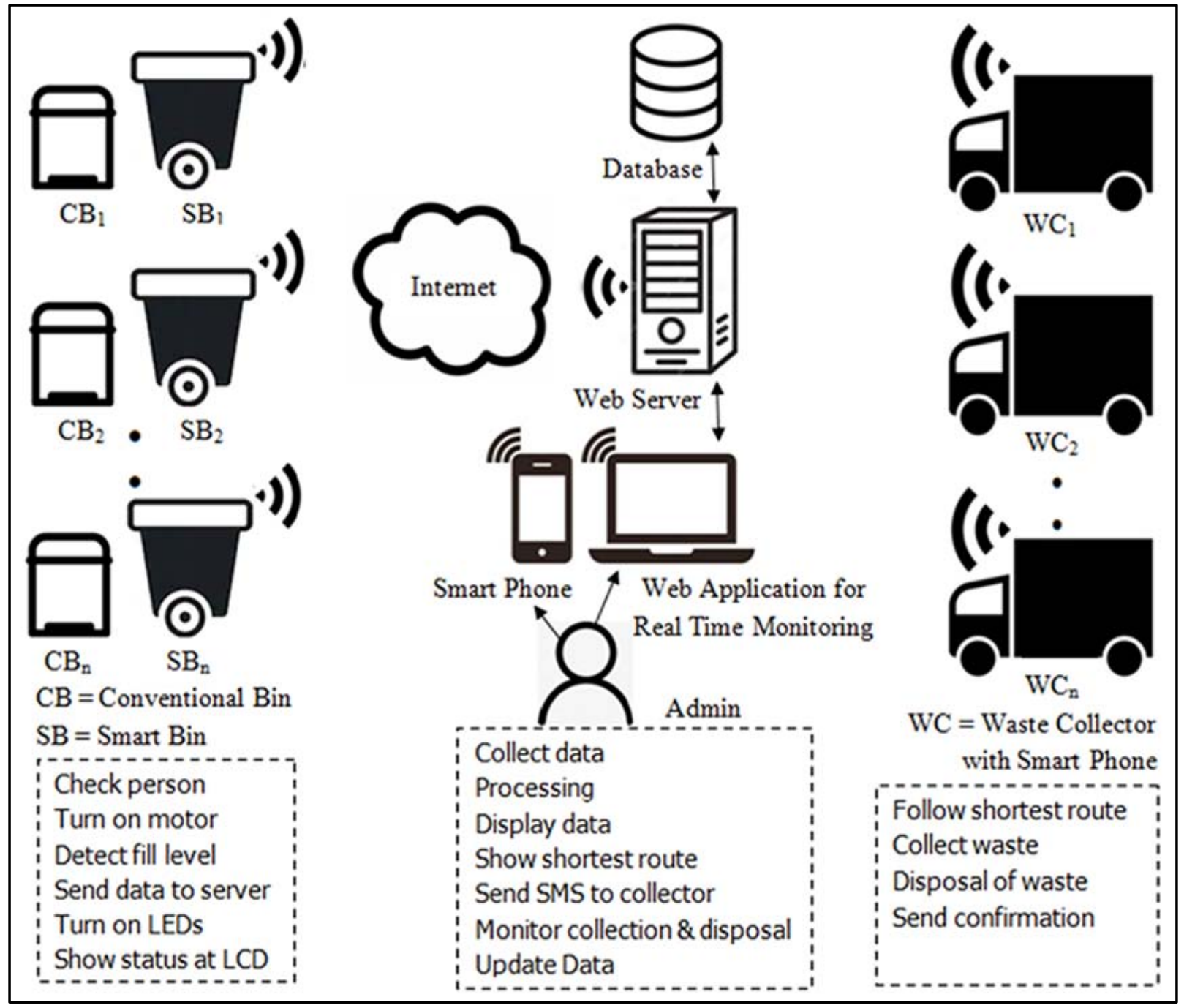

Fig. 1: Illustration of an automated smart waste management system framework for the smart city



Fig. 2: Block diagram of the implemented solar power source 


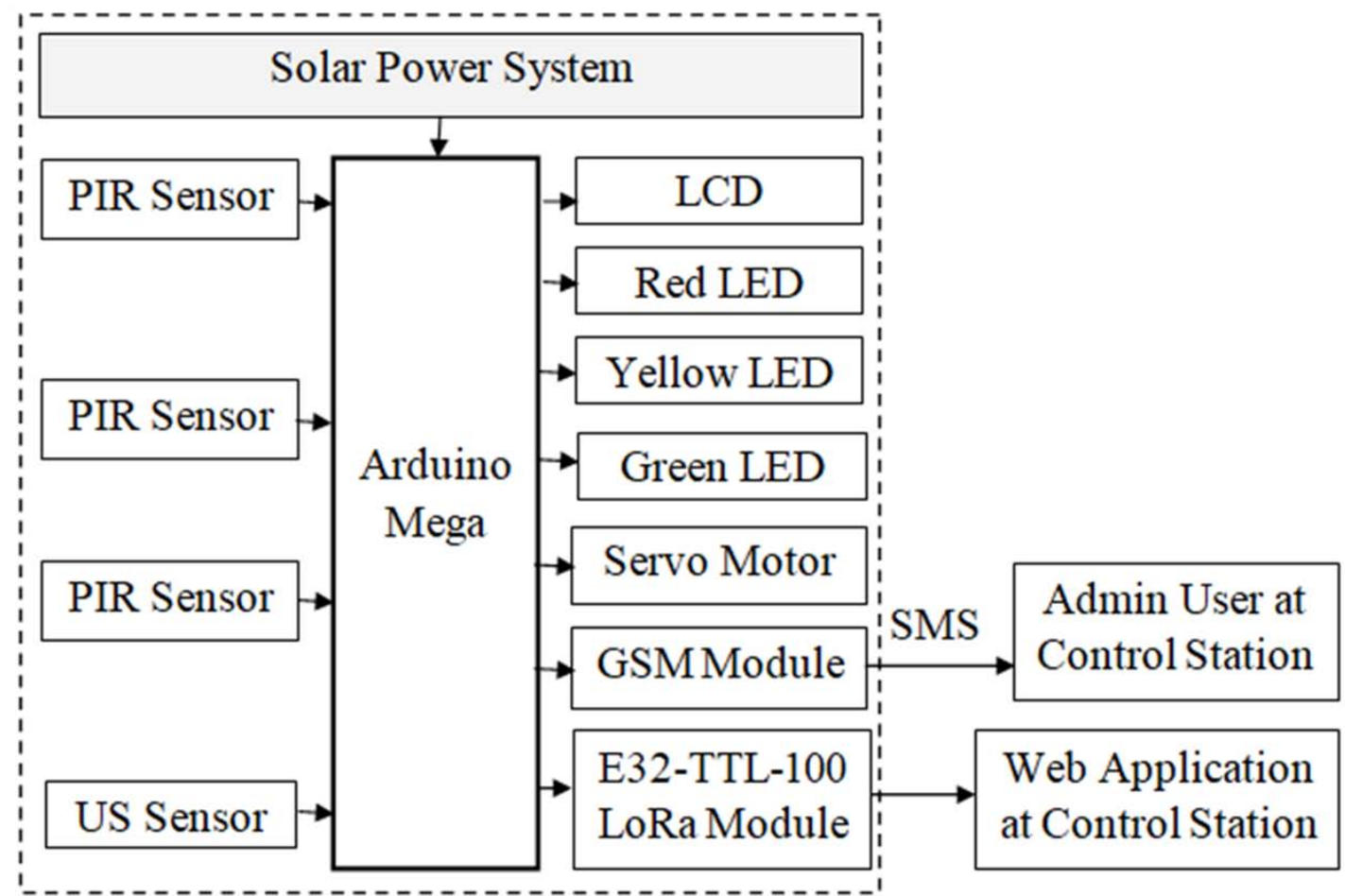

Smart Bin

Fig. 3: Block diagram of the implemented smart bin

Table 1: Waste bin conditions and fill level indicators

\begin{tabular}{|c|c|c|c|c|c|}
\hline \multirow{2}{*}{ Condition } & \multirow{2}{*}{ Threshold } & \multicolumn{3}{|c|}{ Indicators } & \multirow{2}{*}{ Description } \\
\cline { 3 - 6 } & & LED & LCD & SMS & \\
\hline 1 & $0 \%$ & Green & The bin is empty. Please use it. & Not Sent & Empty \\
\hline 2 & $\geq 50 \%$ & Yellow & The bin is semi-full. Please use it. & Not Sent & Semi Loaded \\
\hline 3 & $\geq 90 \%$ & Red & The bin is full. Please use the conventional bin. & Sent & Full Loaded \\
\hline
\end{tabular}

c) SMS Notification System

SMS notification system integrated with each smart bin will send SMS to the control station with bin id and name information and notify that the bin is full. A customer complaints module is also added with the SMS notification system so that people can complain to the authority about uncollected waste. In this work, Global System for Mobile communications (GSM) modem is used for SMS notification because GSM Modem can accept any GSM network operator SIM card and capable for SMS control, data transfer, remote control, and logging using GSM network. We can use its RS232 port to communicate and develop embedded applications. Figure 4 shows the block diagram of the implemented SMS notification system.

\section{d) Control Station}

The control station acts as a central point and coordinates all the tasks among the subsystems in the proposed system framework. This control room contains the central server, which hosts the web server, database, and shortest route-finding system for waste disposal. The data sent by the smart waste bins are received and processed by the control station and stored in the database server. The web application for real-time monitoring will provide a GUI for displaying the waste bins data so that the concerned authority can monitor the status of the smart bins, also instruct collection and disposal activities using a web browser from any devices. We have developed a web application for real-time monitoring of the different smart bins and waste collectors. A PC is used as a control station in our research work. Admin sitting in the control room or from anywhere can coordinate all the tasks of the different subsystems of our implemented system using this web application over the Internet. The output of the developed web-based application is represented through the figure 8 to 11 . The front end of this web application is developed by HTML, CSS, and Bootstrap languages, where PHP language is used for the backend process. For database storage and management, MySQL is used in this web application. 
The shortest route-finding system integrated with the web application for real-time monitoring will send the special route map to the concerned waste collector(s) by using Google Map API to reduce collection and disposal time. The Google Maps API supports enhanced Google Maps in other web pages through a simple JavaScript interface. Google Maps API Premier customers can access the API through a secured HTTP connection. In this application, Google maps API is used for indicating the location and status of the bins. AVLS integrated with each WC (vehicle) provides the real-time location of it, and admin can track the WCs using the developed web application. AVLS is worked based on modern GPS technology.

\section{Vil. Results and Discussion}

All components of the proposed system are implemented and tested thoroughly. The overall prototype and experimental results are presented through figure 5 to 11 . Five smart bins are located at different positions in an area. Figure 5 shows the circuits of an implemented smart bin. All the modules are connected with Arduino Mega. Solar power provides the regulated DC power to every part of the trash bin. Figure 6 indicates that Green, Yellow, and Red LEDs mounted in the implemented smart bin are turned on when the bin is Empty, half-loaded, and full-loaded condition respectively. This fill level status is also represented in the LCD. The snapshot of the received SMS at the control station from Smart Bin1 (SB1) is depicted in figure 7 ; similarly, every smart bin will confirm the admin of the control room through SMS that the bin is full truly. Figure 8 graphically shows the fill level measurement of the smart bins by the progressive bar chart. From this figure, it is clear that SB1, SB3, SB4, and SB5 are full where SB2 is semi-full. We can see the detailed information of a bin like bin id and location etc. by clicking the View Details button at the right of the respective progressive bar. When a smart bin will 90\% full, the web application will display the filling alert notification on the map after processing all the data from that bin shown in figure 9. So, the control station gets fill level alerts by both web-based and SMS based notification. Admin can generate the shortest route in the map for waste collectors shown in figure 10, and waste collectors can view this route in their smart phone. In this work, two medium-size robotic car kits integrated with AVLS are used as a waste collector. Admin can track the waste collector and monitor the waste collection and disposals activities shown in figure 11. From this figure, it is seen that WC1 is collecting waste following the shortest route map, and WC2 is at the vehicle garage.

\section{Vili. Conclusion}

The implemented smart waste management system using Internet of Things (IOT) and cloud computing offered automation through cyber-physical systems, which can change the way of the waste management process. To keep our environment clean and dirt free by a smart solution, this proposed system can be very effective with the reasonable cost in terms of manipulating waste for any municipal and urban areas in both developed and developing countries. Both residential and commercial areas can be digitalized and modernized using this system, which can offer smart and green surroundings that can provide long life for the citizens. Only smart bins rather than the total system can be installed in educational institutions like the university campuses, hospital areas, mega shopping mall, etc. to ensure a healthy environment. Moreover, after proper disposal of waste and garbage materials into the disposal site, the recycling industry can convert these waste and garbage materials into valuable wealth of our country by precise sorting.



Fig. 4: Block diagram of the implemented SMS notification system 


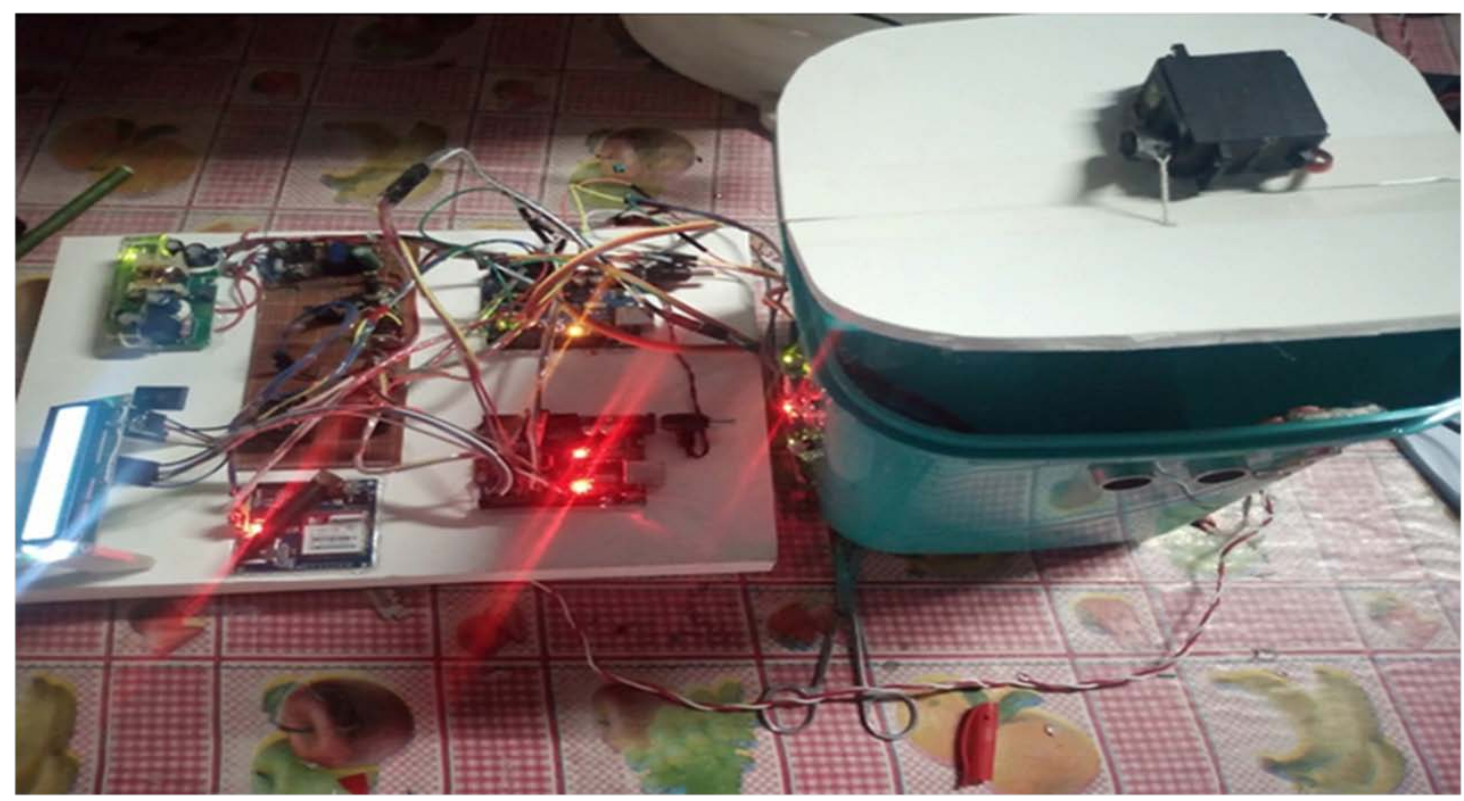

Fig. 5: Circuits inside an implemented Smart Bin

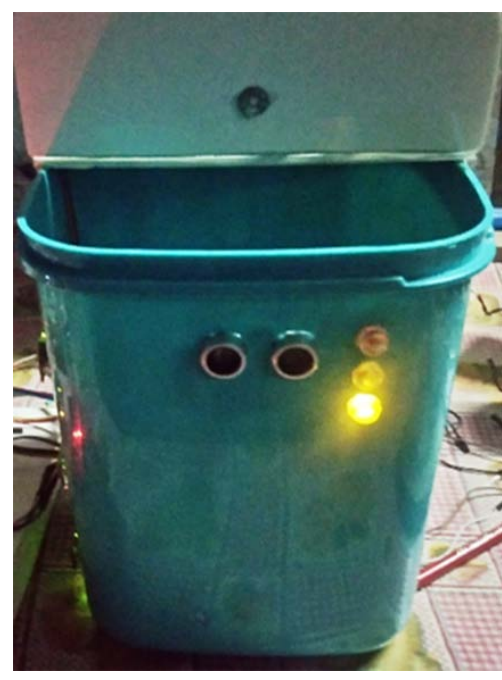

(a)



(b)

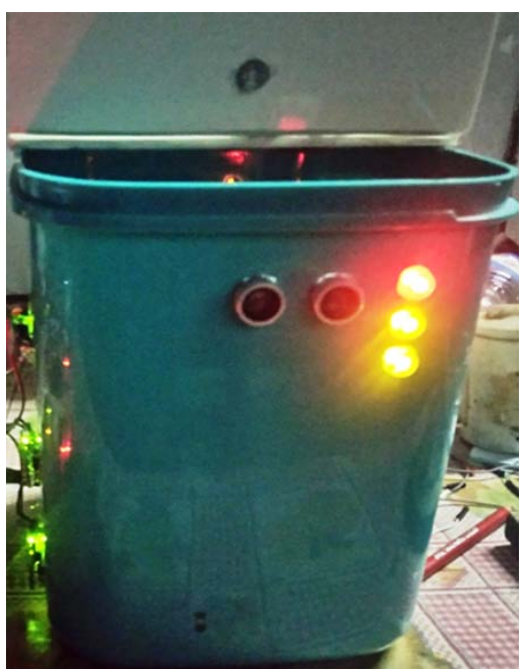

(c)

Fig. 6: Empty, half loaded and full loaded condition of the smart bin indicated by (a) Green, (b) Yellow, and (c) Red LED respectively

Module1-SB1

The Bin is full, plz clear

$$
\text { GP skitto D 9:19 PM }
$$

Type text message

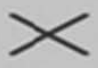

$160 / 1$

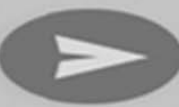

Fig. 7: Admin received SMS at control station from Smart Bin1 (SB1) during full loaded condition 


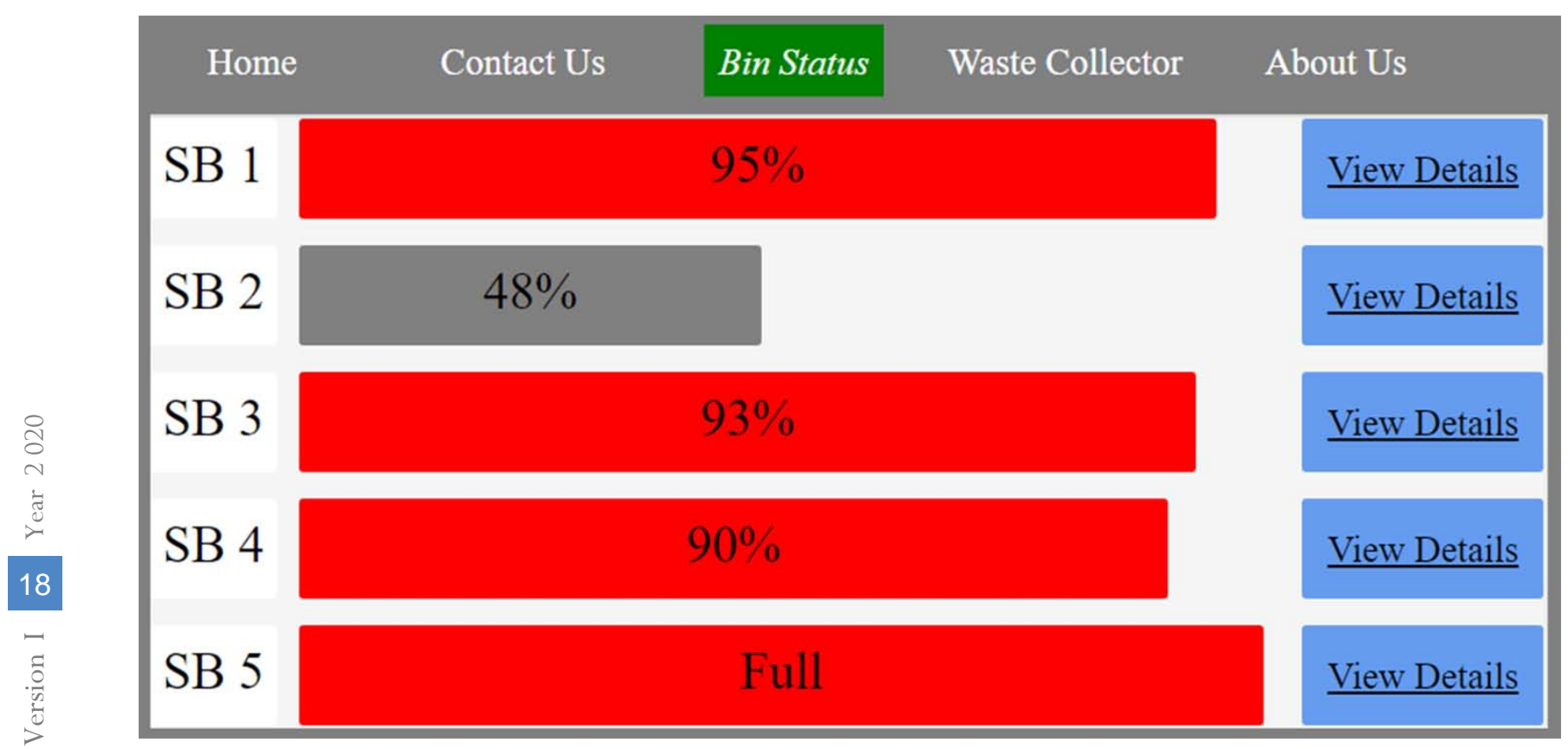

Fig. 8: Real time filling level status of the smart bins at the control station

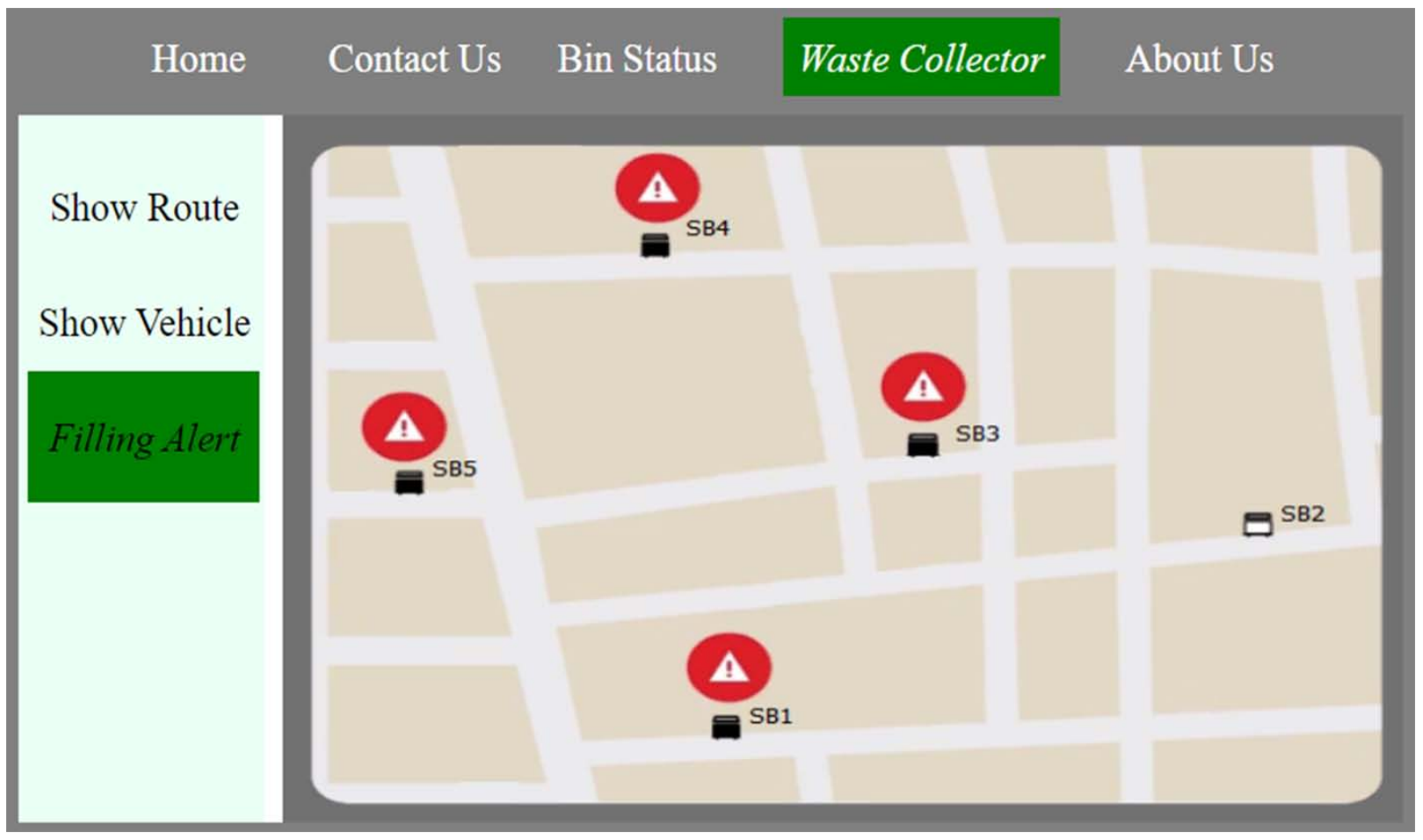

Fig. 9: Filling alert notifications from different smart bins at the control station 




Fig. 10: Shortest route map generation for the waste collectors



Fig. 11: Real time tracking of collection and disposal activities

References Références Referencias

1. Kellow Pardini, Rodrigues, Sergei A. Kozlov, Neeraj Kumar, Vasco Furtado, "IoT-Based Solid Waste Management Solutions: A Survey," Journal of Sensors and Actuator Networks, pp.1-25, 2019.

2. B. N. Silva, M. Khan, and K. Han, "Towards sustainable smart cities: a review of trends, architectures, components, and open challenges in smart cities," Sustainable Cities and Society, vol. 38, pp. 697-713, 2018.

3. Anagnostopoulos, Zaslavsky, Kolomvatsos, Medvedev, Amirian, Morley, "Challenges and Opportunities of Waste Management in loT-enabled Smart Cities: A Survey," IEEE Transactions on Sustainable Computing, pp. 275-289, 2017. 
4. Parkash and V. Prabu, "IOT based waste management for smart city," International Journal of Research on Computer and Communication Engineering., vol. 4, no. 2, 2016.

5. S. S. Navghane, M. S. Killedar, and V. M. Rohokale, "IoT Based Smart Garbage and Waste Collection Bin," International Journal of Advanced Research in Electronics and Communication Engineering, vol. 5, no. 5, pp. 1576-1578, 2016.

6. Dhaarani T G, Ramya Shree G, Sabitha K, Venkatesh C, Praveen Kumar D, "Automated self navigating smart dustbin using IOT," International Journal of Intellectual Advancements and Research in Engineering Computations, Vol. 6, No. 1, pp 62 65, 2018.

7. F. A. Samiul Islam, "Solid Waste Management System in Dhaka City of Bangladesh," Journal of Modern Science and Technology, pp. 192 - 209, September 2016.

8. Farjana Nasrin, "Waste Management in Bangladesh: Current Situations Suggestions for Action," International Research Journal of Social Sciences, pp. 36-42, October 2016.

9. Mohammad Rasel Kabir, "Municipal Solid Waste Management System: A Study on Dhaka North and South City Corporations," Journal of Bangladesh Institute of Planners, pp. 35-48, 2016.

A. A. J. Jim, R. Kadir, M. A. A. Mamun, A. A. Nahid, and M. Y. Ali, "A noble proposal for Internet of garbage bins (loGB)," Smart Cities, vol. 2, no. 2, pp. 214-229, 2019.

10. L. Alvaro, J. Caridad, J. De Paz, G. V. Gonz alez, and J. Bajo, "Smart waste collection system with Iow consumption LoRa WAN nodes and route optimization," Sensors, vol. 18, no. 5, pp. 18041282, 2018.

11. M. V. Bueno Delgado, J. L. Romero Gazquez, P. Jim Enez, and P. Pavon Mariño, "Optimal path planning for selective waste collection in smart cities," Sensors, vol. 19, no. 9, pp. 1973, 2019.

12. Wijaya, Zainuddin, Niswar, "Design a smart waste bin for smart waste management," 5th International Conference on Instrumentation, Control, and Automation (ICA), Indonesia, pp. 62-66, August 2017.

13. Monika K A, Nikitha Rao, Prapulla S B and Shobha G, "Smart Dustbin- An Efficient Garbage Monitoring System", International Journal of Engineering Science and Computing, Vol. 6, No. 6, pp. 71137116, 2016.

14. M. Hannan, M. Akhtar, R. A. Begum, H. Basri, A. Hussain, and E. Scavino, "Capacitated vehiclerouting problem model for scheduled solid waste collection and route optimization using PSO algorithm," Waste Management, vol. 71, pp. 31-41, 2018.
15. M. Cerchecci, F. Luti, A. Mecocci, S. Parrino, G. Peruzzi, and A. Pozzebon, "A low power loT sensor node architecture for waste management within smart cities context," Sensors, vol. 18, no. 4, p. 1282, 2018.

16. Mohd Yusof N, Jidin AZ, Rahim MI, "Smart Garbage Monitoring System for Waste Management," MATEC Web of Conferences, 97:01098, 2017.

17. Parkash and V. Prabu, "IOT based waste management for smart city," International Journal of Research on Computer and Communication Engineering, vol. 4, no. 2, 2016.

18. S. S. Navghane, M. S. Killedar, and V. M. Rohokale, "IoT Based Smart Garbage and Waste Collection Bin," International Journal of Advanced Research in Electronics and Communication Engineering, vol. 5, no. 5, pp. 1576-1578, 2016.

19. N. Sharma, N. Singha, and T. Dutta, "Smart Bin Implementation for Smart Cities," International Journal of Science and Engineering Research., vol. 6, no. 9, pp. 787-791, 2015.

20. Omar MF, Termizi AAA, Zainal D, Wahap NA, Ismail NM, Ahmad N, "Implementation of spatial smart waste management system in Malaysia," IOP Conference Series on Earth and Environmental Science, 37 [1], 2016.

21. Shyamala S, Sindhe K, Muddy V, Chitra C, "Smart waste management system," International Journal of Scientific Development and Research [IJSDR],1[9], 2016. 